\title{
Quantifying the genetic risk for the development of axial SpA - could this become a diagnostic tool?
}

Professor B Paul Wordsworth ${ }^{1,2}$, Dr Carla J Cohen ${ }^{1} \&$ Dr Matteo Vecellio ${ }^{1}$

1. Nuffield Department of Orthopaedics, Rheumatology and Musculoskeletal Sciences, Institute of Musculoskeletal Sciences, Botnar Research Centre, University of Oxford, Oxford OX3 7LD, UK

2. Address for correspondence: Prof BP Wordsworth, Botnar Research Centre, Nuffield Orthopaedic Centre, Headington, Oxford, OX3 7LD, UK

Telephone 44(0)1865741155; Mobile 44(0)7545876550

Email: paul.wordsworth@ndorms.ox.ac.uk

NO FAX facility

Word Count: 2482

\section{Abstract}

Purpose of review: To assess the utility of recent genetic findings in ankylosing spondylitis and axial spondyloarthropathy in relation to diagnostic testing, prognosis and responses to biologic treatment and the development of new therapies.

Recent Findings: Ankylosing spondylitis and other forms of spondyloarthropathy are polygenic with more than 100 genes contributing to disease susceptibility. The role of genes in determining the outcome of the disease and response to treatment is less clear. Here we review some of the progress that has been made over the past decade in understanding the genetic contribution to these diseases and how this may be used to inform the development of new treatments. In those with a high pre-test probability of spondyloarthropathy HLA-B27 testing can increase the post-test predictive value to almost $100 \%$ in some cases. There are currently no reliable genetic predictors of disease severity or response to treatment.

\section{Summary}

The utility of HLA-B27 as a diagnostic tool when coupled with careful clinical assessment is well established but other genetic markers probably have relatively little to add. In contrast, novel drug targets are likely to be identified from genetic association studies.

\section{Key words:}

Spondyloarthropathy, ankylosing spondylitis, genetic markers, HLA-B27

\section{Introduction}

As a fourth year medical student at London's Westminster Hospital in the early 1970s one of us was lucky enough learn about ankylosing spondylitis (AS) from Derrick Brewerton, little realizing that it 
would subsequently occupy much of his working life. At that time Brewerton and others were just about to publish the iconic association between AS and HLA-B27 (then known as HL-Aw27) [1, 2]]. Arguments about the relative importance of nature and nurture in the aetiology of many rheumatic diseases were already being rehearsed, particularly in relation to rheumatoid arthritis [3] but the tools for investigating the genetic component of any disease (even monogenic disorders) were then so limited that to call them rudimentary seems generous. The key insight of Brewerton and his colleague Frank Dudley Hart was that the relatively high frequency of familial recurrence of AS (sibling recurrence risk about $7 \%$ ) indicated a strong genetic predisposition to the disease. Crucially, their research was facilitated by the increasing range of transplantation antigens for use as genetic markers. Collaboration with David James, a transplant immunologist at the Anthony Nolan Centre just around the corner from The Westminster, underpinned much of this HLA-B27 work and the rest, as they say, is history. The HLA-B27 association with AS (relative risk 120) is still one of the strongest genetics risks for a polygenic disorder and actually prompted many to believe that AS was monogenic. Subsequently we have demonstrated by twin studies that most of the population variance for AS can be explained by genes but that only about one-third of this can be accounted for by HLA-B27 [4]. Genetic factors also make a contribution to the severity of the disease [5]. Many of the questions from that era about the genetic contribution to AS are as relevant today as they were then. What is the mechanism behind the HLA-B27 association? Are other genes involved? If so, how many? How useful is this genetic knowledge for determining the diagnosis or prognosis of AS, and can we use this knowledge to develop new therapies? Well - we still don't know the mechanism of the HLA-B27 association after 45 years; there are probably well over 100 genetic influences involved, some of which have given us useful insights into potential therapies; and the role of these genes in facilitating diagnosis and/or prognosis is somewhat controversial.

\section{Spondyloarthropathies and ankylosing spondylitis}

For the purposes of this article I use the term spondyloarthropathy (SpA) to refer to those arthropathies with a variable predilection for the spine and sacroiliac joints, and axial SpA (axSpA) to embrace a range of disorders that includes AS, psoriatic arthritis, reactive arthritis and some of the arthropathies associated with inflammatory bowel disease. For practical purposes I do not believe that semantic arguments relating to the nosology of these conditions materially affect my conclusions about the utility of our increasing genetic knowledge about these conditions. According to the Assessment of Spondyloarthritis international Society (ASAS) individuals may be classified as having non-radiographic axSpA ( $n r-A x S p A)$ according to criteria that either include magnetic resonance imaging (imaging criteria) or not (clinical criteria); HLA-B27 testing is an absolutely crucial component of the latter [6]. To what extent those with nr-axSpA represent a form of early ankylosing spondylitis is a moot point but not all cases of nr-axSpA ultimately appear to develop AS over time [7]. Further, there are reservations about the robustness of the "clinical" (non-imaging) criteria for the diagnosis of $\mathrm{nr}$-axSpA. In this regard it is interesting that there are differences in the genetic makeup of two distinct but related cohorts with $\mathrm{SpA}$ - one fulfilling the ASAS imaging criteria for axSpA and the other the modified New York radiographic criteria for AS [8].

\section{HLA-B27 and AS/axSpA}

Broadly speaking the HLA-B27 association with SpA is maintained across different ethnic groups, and the prevalence of the disease generally reflects the frequency of HLA-B27 in different populations. 
For example, its prevalence is particularly high in circumpolar regions where the general population prevalence of HLA-B27 may be in excess of $25 \%$ in some ethnic groups; in contrast, the disease is uncommon in sub-Saharan Africa where the prevalence of HLA-B27 is typically $<0.5 \%$. There are more than 100 distinct allelic variants of HLA-B27 at the DNA level, many of which have only been described in AS cases. However, many of these alleles are so rare that formal population studies to establish causality are impossible. Nevertheless, population studies demonstrate pretty convincingly that most of the more common variants $\left(B^{*} 2705, B^{*} 2702, B^{*} 2704, B^{*} 2707, B^{*} 2708\right)$ are associated with $A S$ and that the strength of this association appears to be quite similar (if not identical). In contrast, the associations with HLA-B*2703 (in West Africa), B*2706 (in Asia) and B*2709 (in Sardinia) do appear to be weaker or even absent. The HLA-B27 association may also be weaker in southern than northern Europe. For example, a recent study from Turkey [9] indicates that the frequency of HLA-B27 among AS cases is only 70\% compared with $85 \%$ in our UK sample of 8,500 cases. This study confirmed earlier reports of a somewhat weaker association with AS in Turkey where there is also a lower HLA-B27 frequency (2.6\%) in the general population [10]. There also seems to be a broader range of HLA-B27 subtypes in the Turkish AS patients than in more northerly European populations (including HLA-B*2702, *2705, *2707, *2711, *2713, *2715, and *2723); none of the Turkish AS cases had HLA-B*2701 or *2708 despite the presence of these alleles in the general population at frequencies of 4 and $2.7 \%$, respectively [10]. The explanation(s) for the HLAB27 association with AS remains as elusive as ever. Possible mechanisms include: (1) the arthritogenic peptide hypothesis; (2) inflammatory stress responses in the endoplasmic reticulum due to accumulation of abnormally folded HLA-B27; and/or (3) unusual activity of the immune system due to interactions between HLA-B27 homodimers and killer immunoglobulin-like receptors (KIR) on some CD4 positive T-cells. These have been extensively reviewed elsewhere [11, 12]. The role of HLA class 1 molecules like HLA-B27 in the pathogenesis of AS has been further emphasized in recent years by the association of other components of the antigen processing and presentation pathway with AS. In particular, the endoplasmic reticulum associated amino peptidases ERAP1, ERAP2, and LNPEP (leucyl/cystinyl aminopeptidase) show strong associations with AS and there is a high degree of synergistic interaction with HLA-B27 in the case of ERAP1 [13, 14, 15]. Further, within the major histocompatibility complex there are several additional AS associations (much weaker than with HLA-B27), including with other HLA-B genes, the HLA-A, HLA-DR and HLA-DP loci [15]. Disease associated variants of ERAP1 can alter the repertoire of peptides available for binding to and presentation by HLA-B27, which in turn could have a significant influence on any of the pathogenic mechanisms proposed above [16]. One interesting proposal suggested that the ERAP1 association could be attributed unusual rare ERAP1 alleles and haplotype combinations restricted largely to AS cases; this was hypothesised to have a major potential effect on the HLA class 1 peptide repertoire [17]. However, this has now been disproved and the ERAP1 is actually restricted to the different functional effects of a few relatively common variants on HLA class 1 peptide antigen trimming [18].

\section{Other genes in AS}

More than 100 genetic associations have now been proposed in AS [19] but only a few of these result in amino acid substitutions that affect function, such as the coding change in the IL-23 receptor cytoplasmic tail that affects signalling and the ERAP1 variants that affect peptide trimming in the endoplasmic reticulum $[13,14,15,16,20]$. The vast majority of associated SNPs are in noncoding regions of the genome where it seems likely that that many have regulatory functions although these remain to be precisely defined [21, 22]]. At least some of these appear to cluster in related functional groups such as the IL23 related pathways [14]. The observation that loss of function variants of ERAP1 are protective against AS raises the possibility that small molecule inhibitors of these endopeptidases could be developed as drugs for AS and related disorders $[12,13]$. 


\section{Utility of genetic markers in diagnosis}

Extrapolation from the results of AS recurrence in twins suggests that well over $90 \%$ of the population variance (broadly speaking what determines whether you or I will develop AS) is genetically determined [4]. This does not exclude an extrinsic trigger but suggests that any such factor is likely to be so common that most of us will encounter it at some time in our lives (twin studies may underestimate the importance of such shared environmental factors). Given our greatly increased knowledge of the genetic component of AS over the past decade it is therefore easy to suppose that we should therefore be in a much stronger position to use this knowledge for diagnostic and prognostic purposes. However, the reality is rather different. The strength of the association between AS and HLA-B27 is remarkable but it still contributes only about one-third of the genetic component of the disease. The remaining polygenic contribution therefore accounts for the majority of the population variance for AS. Although the precise genes responsible for most of the single nucleotide polymorphism (SNP) associations with AS are still unresolved one can still use these markers to define an individual's overall susceptibility. Theoretically, high throughput genotyping platforms could allow us to type all the known AS associated SNPs quickly and, these days, relatively cheaply to give a more accurate assessment of risk in a given individual. While this is true it fails to take account of a fundamental statistical rule that when applying a test of this sort its value is determined by the pre-test probability of obtaining a positive result. This is well exemplified by the example of HLA-B27 testing alone in the diagnosis of AS/axi SpA. Assuming a prevalence of axSpA of about $5 \%$ in those with chronic back pain $[23,24]$ estimated that in the absence of any other features suggestive of SpA the pre-test probability of SpA was $14 \%$ but if HLA-B27 was present the post-test probability of axial SpA increased to $59 \%$. If 1 or 2 other SpA features were present the pretest probability of axial SpA was $35-70 \%$, increasing to $80-90 \%$ if HLA-B27 was positive. The presence of 3 or more additional features had a pre-test probability of $>90 \%$, which increased to nearly $100 \%$ in the presence of HLA-B27. So, while it may be true that a battery of genetic tests may give better sensitivity for diagnosing AS/axial SpA than HLA-B27 alone this is highly unlikely to supplant the judicious application of some very simple questions in the clinical setting.

Although there is good evidence that the severity of AS is at least in part heritable the contribution of individual genes towards this has been relatively little explored to date. HLA-B27 positivity is associated with earlier age of onset and strongly with uveitis, of course [25]. Radiographic severity (assessed by the modified Stoke AS spine score in 1537 cases) has been tentatively associated with the candidate genes RANK- receptor activator of NF kappa B and cyclooxygenase-1 but such studies will require replication [26]. Of interest, no association was observed between radiographic severity and HLA-B27 in this study.

\section{Genetic markers for predicting severity and responses to treatment}

The value of individual genetic markers or combinations of markers for predicting response to treatment is often proposed as a means of delivering "personalised medicine" to individual patients [27]. Certainly genetic analysis offers a realistic way of achieving this in oncology where the nature of the mutations in the tumour can guide the most appropriate form of therapy and help to change therapies in the event of tumour relapse. However, in the case of a systemic disease like AS this seems unlikely to me. No two patients with AS are likely to have exactly the same set of genetic predispositions to the disease but this does not help to predict response to therapy. For example, the identification of an AS protective effect from the IL23R rs11209026 polymorphism in the cytoplasmic tail of the interleukin-23 receptor, which disrupts its signalling, served to highlight the importance of IL23 driven pathways in the pathogenesis of AS [13, 14, 15, 20]. This led to the targeting of IL-17 by therapeutic monoclonal antibodies as a highly successful therapeutic strategy for AS $[28,29]$. However, the successful targeting of IL-17 in this way is not restricted to cases with 
the normally functioning, pro-inflammatory, AS-risk IL23R genotype. One of the reasons for this lies in the fact that there are several other disease associated polymorphisms lying within the IL23 pathway of T-cell development, including IL6, IL12, IL12B, TYK2, STAT3, IL27, IL1R1, IL1R2, and $R U N X 3[12,14]$. Of interest, although the AS association with rs11209026 is robust in Caucasian populations it is monomorphic in Chinese with the consequence that there is, of course, no corresponding disease association in this population. Yet, as far as we can tell secukinumab is effective in Chinese patients, certainly when used for the treatment of psoriasis [30].

\title{
Predicting the outcome of treatment
}

Attempts to use genetic markers of susceptibility to a disease like AS to predict response to treatment have been limited to date and potentially would require large cohorts to distinguish subtle differences. Unfortunately this is made even more difficult by the fact that many of the descriptors of disease activity and severity are fairly blunt instruments (the high degree of correlation between the Bath AS functional and disease activity indices bear testimony to the difficulty of distinguishing current disease activity from chronic disease damage). Further, the use of radiographic criteria of disease severity is plagued by the slow rate of radiographic progression (as judged by new syndesmophyte growth. There are occasional exceptions, such as the reported value of the ERAP1 rs30187 SNP in predicting AS responses to secukinumab in a small study [28] but these demand replication and validation in large data sets. We have recently been interested in the possibility that the rs 1800693 SNP in TNFRSF1A (encoding a truncated soluble form of the tumour necrosis factor receptor) because it could have anti-inflammatory properties and is associated with protection against AS (but susceptibility to multiple sclerosis). As such it seemed a good candidate for influencing the severity of AS. However, we were unable to demonstrate any influence on age of onset, disease severity scores, intention to treat with biologics or the efficacy of biologics in a sample of nearly 3000 cases [31].

\section{Conclusion}

The utility of HLA-B27 in the diagnosis of AS/SpA is undeniable but the utility of additional genetic markers in making the diagnosis or predicting outcome is unclear. In current clinical practice the application of careful clinical questioning coupled with HLA-B27 testing and MRI of the sacroiliac joints when appropriate, provides a diagnostic sensitivity of approaching 100 per cent $[6,23,24,32]$. Genetic association studies are likely to continue to contribute significantly to the identifcation of new drug targets in AS/SpA.

\section{Summary Points}

- Ankylosing spondylitis is a polygenic disease with contributions from more than 100 genes

- HLA-B27 testing is diagnostically very valuable in cases with a high pre-test probability

- Other genetic markers currently add little to HLA-B27 testing

- AS susceptibility markers do not usefully predict severity of AS or response to treatment

- The genetics of AS/SpA can help to identify potential drug targets for treatment

\section{References}

\author{
*of interest \\ ** of special interest
}


1. Brewerton DA, Hart FD, Nicholls A, Caffrey M, James DC, Sturrock RD. Ankylosing spondylitis and HL-A 27. Lancet. 1973; 1(7809): 904-7.

2. Schlosstein L, Terasaki PI, Bluestone R, Pearson CM. High association of an HL-A antigen, w27, with ankylosing spondylitis. N Engl J Med. 1973; 288(14):704-6.

3. Lawrence JS . Rheumatoid arthritis--nature or nurture. Ann Rheum Dis. 1970; 29(4): 357-79.

4. Brown MA, Kennedy LG, MacGregor AJ, Darke C, Duncan E, Shatford JL, Taylor A, Calin A, Wordsworth P. Susceptibility to ankylosing spondylitis in twins: the role of genes, HLA, and the environment. Arthritis Rheum. 1997; 40(10): 1823-8.

5. Brown MA, Brophy S, Bradbury L, Hamersma J, Timms A, Laval S, Cardon L, Calin A, Wordsworth BP. Identification of major loci controlling clinical manifestations of ankylosing spondylitis. Arthritis Rheum 2003; 48:2234-39.

6. Rudwaleit M, van der Heijde D, Landewé R, Akkoc N, Brandt J, Chou CT et al. The Assessment of SpondyloArthritis International Society classification criteria for peripheral spondyloarthritis and for spondyloarthritis in general. Ann Rheum Dis 2011; 70(1): 25-31.

7. Robinson PC, Wordsworth BP, Reveille JD, Brown MA. Axial spondyloarthritis: a new disease entity, not necessarily early ankylosing spondylitis. Ann Rheum Dis. 2013; 72(2): 162-4.

8. G. Thomas, D. Willner, P. Robinson, A. Cortes, R. Duan, M. Rudwaleit, N. Akkoc, J. Braun, C. Chou, W. Maksymowych, S. Ozgocmen, E. Roussou, J. Sieper, R. Valle-Oñate, D. van der Heijde, J. Wei, P. Leo, M. Brown and the International Genetics of Ankylosing Spondylitis Consortium. Genetic diagnostic profiling in axial spondyloarthritis: a real world study. Clin Exp Rheumatol 2017; 35: 229-33.

* This study demonstrates that there may be significant genetic differences between different cohorts of patients with SpA

9. Fırat SN, Yazıcı A, Yılmazer B, Coşan F, Savlı H, Cefle A. Low frequency of HLA-B27 in ankylosing spondylitis and its relationship with clinical findings in patients from Turkey. Eur J Rheumatol 2017; 4: 268-71.

*The relationship between HLA-B27 and AS appears more complex in this population than most of Europe

10. Gunal EK, Sarvan FO, Kamali S, Gul A, Inanc M, Carin M, Konice M, ArAl O, Ocal L. Low frequency of HLA-B27 in ankylosing spondylitis patients from Turkey. Joint Bone Spine 2008;75:299-302.

11. de Koning A, Schoones JW, van der Heijde D, van Gaalen FA. Pathophysiology of axial spondyloarthritis: Consensus and controversies. Eur J Clin Invest epub 13 March 2018 https://doi.org/10.1111/eci.12913

*Nice up to date review of the pathophysiology of SpA

12. Hanson A \& Brown MA. Genetics and the Causes of Ankylosing Spondylitis. Rheum Dis Clin N Am 2017; 43: 401-414.

*Good review of our current knowledge of the genetics of AS

13. Evans DE, Spencer CCA, Pointon JJ, Su Z, Harvey D, Kochan G, Oppermann U. et al Interaction between ERAP1 and HLA-B27 in ankylosing spondylitis implicates peptide handling in the mechanism for HLA-B27 in disease susceptibility. Nat Genet 2011; 43:761-7.

14. Cortes A, Hadler J, Pointon JP, Robinson PC, Karaderi T, Leo P, Cremin K et al. Identification of multiple risk variants for ankylosing spondylitis through high-density genotyping of immune-related loci. Nat Genet 2013; 45: 730-738.

15. Cortes A, Pulit SL, Leo PJ, Pointon JJ, Robinson PC Weissman, MH, Ward M et al. Identification of multiple risk variants for ankylosing spondylitis through high-density genotyping of immune-related loci. Nat Comms 2015: EPub 7 April 2015: DOI 10.1038/natcomms8146.

16. Chen L, Fischer R, Peng Y, Reeves E, McHugh K, Ternette N, Hanke T et al. Critical Role of Endoplasmic Reticulum Aminopeptidase 1 in Determining the Length and Sequence of Peptides Bound and Presented by HLA-B27. Arthritis Rheumatol 2014;66:284-94. 
17. Reeves E, Colebatch-Bourn A, Elliott T, Edwards CJ, James E. Functionally distinct ERAP1 allotype combinations distinguish individuals with Ankylosing Spondylitis. Proc Natl Acad Sci (USA) 2014; 111: 17594-17599.

18. Roberts AR, Appleton LH, Cortes A, Vecellio M, Lau J, Watts L, Brown MA, Wordsworth P. ERAP1 association with ankylosing spondylitis is attributable to common genotypes rather than rare haplotype combinations. Proc Natl Acad Sci (USA) 2017; 114: 558-561.

*An important rebuttal of the idea that rare ERAP1 variants are the cause of AS

19. Ellinghaus D, Jostins L, Spain SL, Cortes A, Bethune J, Buhm H, Park YR et al. Analysis of five chronic inflammatory diseases identifies 27 new associations and highlights disease-specific patterns at shared loci. Nat Genet 2016; 48: 510-518.

**Hard going but a really important contribution to our knowledge of the genetics of AS and related disorders based on genetic profiling of disease cohorts from 5 related disease sets. Suggests that there are more than $\mathbf{1 0 0}$ genes involved in AS with more to come.

20. Karaderi T, Harvey D, Farrar C, Appleton LH, Stone MA, Sturrock RD, Brown MA, Wordsworth $\mathrm{P}$, Pointon JJ. Association between the interleukin 23 receptor and ankylosing spondylitis is confirmed by a new UK case-control study and meta-analysis of published series. Rheumatology 2009; 48: 386-389.

21. Roberts AR, Vecellio M, Chen L, Ridley A, Cortes A, Knight JC, Bowness P, Cohen CJ, Wordsworth BP. An ankylosing spondylitis-associated genetic variant in the IL23R-IL12RB2 intergenic region modulates enhancer activity and is associated with increased Th1-cell differentiation Ann Rheum Dis 2016; 75: 2150-6.

22. Vecellio M, Cortes A, Roberts AR, Ellis J, Cohen CJ, Knight JC, Brown MA, Bowness P, Wordsworth BP. Evidence for a second ankylosing spondylitis associated RUNX3 regulatory polymorphism. RMD Open 2018;4:e000628. doi:10.1136/ rmdopen-2017-000628.

* Might there be at least two distinct AS associated polymorphisms in the regulatory region of the RUNX3 gene and do they operate in different cell types? An insight into the potential complexity of genetic associations with AS

23. Rudwaleit $M$ \& Sieper J. Diagnose und fruhdiagnose der ankylosierenden spondylitis. $Z$ Rheumatol 2004; 63:193-202

*Worth reading this in the original German. Rudwaleit has contributed hugely to this field and this early paper says it all really.

24. Rudwaleit M, van der Heijde D, Khan MA, Braun J, Sieper J. How to diagnose axial spondyloarthritis early. Ann Rheum Dis 2004; 63: 535-543.

25. E Jaakkola E, Herzberg I, K Laiho K, Barnardo MCNM, Pointon JJ, Kauppi M, Kaarela K, Tuomilehto-Wolf E, Tuomilehto J, Wordsworth BP, Brown MA. Finnish HLA studies confirm the increased risk conferred by HLA-B27 homozygosity in ankylosing spondylitis. Ann Rheum Dis 2006; 65: 775-80.

26. Cortes A, Maksymowych WP, Wordsworth BP, Inman RD, Danoy P, Rahman P, Stone MA et al. Association study of genes related to bone formation and resorption and the extent of radiographic change in ankylosing spondylitis. Ann Rheum Dis 2015; 74:1387-93.

27. Low SK1, Zembutsu H1, Nakamura Y. Breast cancer: The translation of big genomic data to cancer precision medicine. Cancer Sci 2018;109(3):497-506. doi: 10.1111/cas.13463. Epub 2017 Dec 30.

*Precision medicine in cancer is the modern goal. This is just one example of the use of "omics" towards the goal of tailored therapy. However, there are thousands to choose from - and that is just this month.

28. Baeten D, Baraliakos X, Braun J, Sieper J, Emery P, van der Heijde D, McInnes I et al. Antiinterleukin-17A monoclonal antibody secukinumab in treatment of ankylosing spondylitis: a randomised, double-blind, placebo-controlled trial. Lancet 2013; 382: 1705-13.

29. Baeten D, Sieper J, Braun J, Baraliakos X, Dougados M, Emery P, Deodhar A et al. Secukinumab, an Interleukin-17A Inhibitor, in Ankylosing Spondylitis. N Eng J Med 2015; 373 : 
2534-48.

*The discovery of the genetic association with IL23R probably hastened the application of clinical trials of secukinumab in AS by several years. A sort of proof of concept that genetics can be valuable in the repurposing of drugs

30. Tsai YC1, Tsai TF. A review of clinical trials of biologic agents and small molecules for psoriasis in Asian subjects. G Ital Dermatol Venereol 2016 Aug; 151: 412-31

31. Watts L, Karaderi T, Roberts A, Appleton L, Wordsworth T, Cohen C, Wordsworth P, Vecellio $M$. The severity of ankylosing spondylitis and responses to anti-tumour necrosis factor biologics are not influenced by the tumour necrosis factor receptor polymorphism incriminated in multiple sclerosis. Genes Immun 2018 Mar 10. doi: 10.1038/s41435-0180017-0. [Epub ahead of print]

* The potentially anti-inflammatory effects of this polymorphism made it a good candidate for influencing not only disease susceptibility but also disease severity and the response to anti-TNF biologics but this relatively large study showed otherwise.

32. Taurog JD, Chhabra A \& Colbert RA. Ankylosing Spondylitis and Axial Spondyloarthritis. $N$ Eng J Med 2016; 374: 2563-74.

\section{Acknowledgements}

We should like to thank the National Ankylosing Spondylitis Society (UK) and its members for their long-term financial support and encouragement. The authors appreciate the support of the International Genetics of Ankylosing Spondylitis consortium but acknowledge that the views expressed in this article are personal and may not be shared by all members of the consortium.

\section{Financial support and sponsorship:}

MV received salary support from Arthritis Research UK (grant 21428) and the National Institute for Health research Oxford Biomedical research Centre (A93081); additional financial support came from Arthritis research UK (grant nos. 20773, 20796, 18797 \& 19536).

\section{Conflicts of interest:}

The authors have no conflicts of interest 